\title{
Enantioselectivity of Projection Neurons Innervating Identified Olfactory Glomeruli
}

\author{
Carolina E. Reisenman, ${ }^{1}$ Thomas A. Christensen, ${ }^{1}$ Wittko Francke, ${ }^{2}$ and John G. Hildebrand ${ }^{1}$ \\ ${ }^{1}$ Arizona Research Laboratories, Division of Neurobiology, University of Arizona, Tucson, Arizona 85721-0077, and 2Institut für Organische Chemie, \\ Universität Hamburg, 20146 Hamburg, Germany
}

\begin{abstract}
Projection neurons (PNs) with arborizations in the sexually dimorphic "lateral large female glomerulus" (latLFG) in the antennal lobe (AL) of the moth Manduca sexta previously were shown to respond preferentially to antennal stimulation with ( \pm )linalool, a volatile compound commonly emitted by plants. In the present study, using intracellular recording and staining techniques, we examined the responsiveness of latLFG-PNs to the enantiomers, $(+)$ linalool and ( - )linalool and found that (1) latLFG-PNs are more responsive to antennal stimulation with (+)linalool than with (-)linalool, (2) PNs with arborizations in a glomerulus adjacent to the latLFG are preferentially responsive to (-)linalool, and (3) PNs with arborizations confined to other glomeruli near the latLFG are equally responsive to both enantiomers of linalool. Structure-activity studies showed that the hydroxyl group in this tertiary terpene alcohol is the key feature of the molecule determining the response of enantioselective PNs to linalool. In contrast, the responses of non-enantioselective PNs are less dependent on the alcoholic functionality of linalool. Our findings show that PNs innervating a uniquely identifiable glomerulus respond preferentially to a particular enantiomer of an odor substance. Moreover, PNs with arborizations in a glomerulus adjacent to the latLFG, although less sensitive than latLFG-PNs to linalool, respond preferentially to the opposite enantiomer, demonstrating that information about stimulus-absolute configuration can be encoded in different olfactory glomeruli.
\end{abstract}

Key words: olfaction; enantiomers; odor coding; glomerulus; insect; electrophysiology; intracellular recording

\section{Introduction}

Stereochemistry plays a significant role in structure-activity relationships of chemical messengers (Mori, 2002). A robust example of the importance of chirality in olfaction is the ability of humans to discriminate between $(+)$ and $(-)$ enantiomers of carvone, which smell like caraway and spearmint, respectively (Friedman and Miller, 1971). Discrimination between enantiomers, however, may be limited to certain chiral substances, depending on the receiver (Laska and Teubner, 1999; Laska and Galizia, 2001; Linster et al., 2001). Few studies have examined how enantiomers are represented by patterns of neural activity in the olfactory system. In the laboratory rat, activity-dependent labeling with 2-deoxyglucose and imaging of intrinsic signals revealed that enantiomers that are discriminated in behavioral tests activate distinct but overlapping sets of glomeruli (Linster et al., 2001; Rubin and Katz, 2001), whereas enantiomers that are more difficult to discriminate evoke less distinct patterns of activation (Linster et

\footnotetext{
Received Nov. 24, 2003; revised Jan. 28, 2004; accepted Feb. 3, 2004.

This work was supported by a fellowship to C.E.R. from the Pew Latin American Fellows Program in the Biomedical Sciences of the Pew Charitable Trust and by National Institutes of Health Grant R01-DC-02751 to J.G.H. We thank Drs. Pablo Guerenstein and Hong Lei for valuable help in the early stages of this work, Heather Stein for invaluable technical assistance and for reconstruction of AL glomeruli, Patricia Jansma for technical advice on confocal microscopy, Dr. A. A. Osman for rearing Manduca, Dr. Romina Barrozo for advice about statistics, and other members of our research group for helpful discussions. We are grateful to three anonymous reviewers for their useful comments and improvements in this manuscript.

Correspondence should be addressed to Dr. Carolina Reisenman, Arizona Research Laboratories, Division of Neurobiology, University of Arizona, P.0. Box 210077, Tucson, AZ 85721-0077. E-mail: carolina@neurobio.arizona.edu.

DOI:10.1523/JNEUROSCI.5192-03.2004

Copyright $\odot 2004$ Society for Neuroscience $\quad 0270-6474 / 04 / 242602-10 \$ 15.00 / 0$
}

al., 2002). Furthermore, the complete representation of carvone in the olfactory bulb is not essential for enantiomeric discrimination (Slotnick and Bisulco, 2003). Few attempts to relate such patterns of glomerular activation to particular types of neurons have been reported. In mice, the enantiomers of carvone activate distinct but overlapping sets of olfactory receptor cells (ORCs) (Ma and Shepherd, 2000) and mitral-tufted cells (Lehmkuhle et al., 2003), whereas in the fly Drosophila melanogaster, these enantiomers activate similar patterns of ORCs and glomerular projection (output) neurons (PNs) (Wang et al., 2003).

In certain species of insects, chirality is important for the specificity of ORCs tuned to components of pheromones (Tumlinson et al., 1977; Leal, 1996; Mori, 1998). With a few exceptions (Wibe et al., 1998; Stranden et al., 2002, 2003), however, little is known about the enantiospecificity of ORCs responding to nonpheromonal odor compounds. To our knowledge, no study in vertebrates or invertebrates has used intracellular recording to examine the enantioselectivity of PNs innervating identified glomeruli. Our ability to characterize individual PNs with arborizations in identified, recognizable glomeruli in the antennal lobes (ALs) of the sphinx moth Manduca sexta (hereinafter referred to as Manduca) makes this species a useful model for such studies.

Two large female-specific glomeruli (LFGs) are prominent in the ALs of adult female Manduca (Rospars and Hildebrand, 2000). The LFGs might play important roles in female-specific behaviors, such us the location and selection of appropriate host plants for oviposition. We reported previously that PNs with arborizations in one of these female-specific glomeruli, the lateral 
LFG (latLFG), respond preferentially to antennal stimulation with ( \pm )linalool (Roche King et al., 2000). Linalool is found among the many volatile substances (volatiles) emitted by plants, including Manduca's host plants (Loughrin et al., 1990; Fraser et al., 2003). The readily identifiable latLFG thus is favorable for studies of the response selectivity of uniglomerular PNs to enantiomers of a chiral odor substance. Using intracellular recording and staining methods, we examined the responses of PNs with arborizations confined to the latLFG, and of PNs of several other neighboring glomeruli, to antennal stimulation with $(-)$ linalool and $(+)$ linalool and structurally related volatiles.

\section{Materials and Methods}

Preparation. Manduca sexta (L.) (Lepidoptera: Sphingidae), reared in the laboratory on artificial diet, were used for these studies when $1-3 \mathrm{~d}$ after eclosion. Animals were dissected and prepared for intracellular recording by established procedures (Roche King et al., 2000). After the AL had been desheathed, the preparation was superfused continuously with physiological saline solution containing (in $\mathrm{mM}$ ): $150 \mathrm{NaCl}, 3 \mathrm{CaCl}_{2}, 3$ $\mathrm{KCl}, 10$ TES buffer, $\mathrm{pH}$ 6.9, and 25 sucrose (Christensen and Hildebrand, 1987).

Stimulation. A few flagellameres were removed from the tip of the antenna, and that cut end of the antenna was inserted into a borosilicate capillary tube $[1 \mathrm{~mm}$ outer diameter (o.d.), $0.75 \mathrm{~mm}$ inner diameter (i.d.); A-M Systems, Carlsborg, WA] filled with physiological saline solution. This capillary tube served both as a holder to position the antenna and as an electrode for monitoring antennal [electroantennogram (EAG) ] responses to olfactory stimulation. The EAG signal was amplified 50-fold through a DC electrometer (M-707, WPI Instruments, Sarasota, FL). An L-shaped glass tube ( $1 \mathrm{~cm}$ i.d.; long leg, $15 \mathrm{~cm}$; short leg, $9 \mathrm{~cm}$ ), with its outlet at $\sim 15 \mathrm{~mm}$ from the antenna, delivered a constant flow of humidified, charcoal-filtered air at a velocity of $1.9 \mathrm{l} / \mathrm{min}$. The outlet of the tube, flattened to $0.5 \times 1.5 \mathrm{~cm}$, was aimed at and aligned with the longitudinal axis of the antennal flagellum. Odor substances were injected into the air stream via a motor-driven syringe olfactometer (Selchow, 1998). The tip of a stimulus syringe mounted in the olfactometer was inserted into a hole in the side of the glass tube, $11 \mathrm{~cm}$ behind the outlet. The olfactometer was activated by a computer-controlled command pulse (customized ASYST software; Keithly Instruments, Rochester, NY). For each trial, a single pulse $(2 \mathrm{ml}, 200 \mathrm{msec})$ was delivered from the syringe to the antenna by injection into the air stream. Thus, odor stimuli injected (at a velocity of $10 \mathrm{ml} / \mathrm{sec}$ ) into the air stream (flowing constantly at $32 \mathrm{ml} / \mathrm{sec}$ ) were diluted $\sim 1: 4$. A funnel connected to a negative-pressure line was positioned near and behind the preparation to remove odors after stimulus delivery.

The odor substances used in this study (Fig. 1) were as follows: [purities reported by the manufacturers except for $(+)$ linalool]: (1) from coriander oil by preparative gas chromatography (stationary phase: $2,6-$ dimethyl 3-pentyl- $\gamma$-cyclodextrin; column: $2 \mathrm{~m} \times 5.3 \mathrm{~mm}$ i.d. run at $\left.75^{\circ} \mathrm{C}\right)$ : (+)linalool $[(+) 3,7$-dimethyl-1,6-octadien-3-ol, 99.9\% pure based on gas chromatographic analysis]; (2) from Fluka (Buchs, Switzerland): (-)linalool [(-)3,7-dimethyl-1,6-octadien-3-ol; catalog \#62139, $>95 \%$ ], ocimene (3,7-dimethyl-1,3,6-octatriene, catalog \#74730; 95\% mixture of isomers), and 2-octanone (catalog \#53220; >97\%); (3) from Sigma-Aldrich (St. Louis, MO): $(+) \beta$-citronellene $[(+)-3,7$-dimethyl-1,6-octadiene; catalog $\# 27475,>98.5 \%],(-) \beta$-citronellene [(-)3,7-dimethyl-1,6-octadiene; catalog \#27477; >90\%], nerol (cis3,7-dimethyl-2,6-octadien-1-ol, catalog \#26890-9; 97\%), geraniol (trans-3,7-dimethyl-2,6-octadien-1-ol; catalog \#G-5135; 98\%), trans- $\beta$ myrcene (7-methyl-3-methylene-1,6-octadiene; catalog \#M10,000-5; 92.5\%; hereinafter referred to as myrcene), benzyl alcohol (catalog \#30519-7; 99.8\% pure), hexan-1-ol (catalog \#47142; 99\%; hereinafter referred to as hexanol), geranylacetone (trans-6,10-dimethyl-5,9-undecadien-2-one; catalog \#32867-7; 96\% pure), ( \pm )2-octanol (catalog \#O450-4; 97\%), and ( \pm$) \beta$-citronellol [( \pm$) 3,7$-dimethyl-6-octen-1-ol; catalog \#C8,320-1; 95\%]; and (4) from Tokyo Chemical Industries (Tokyo, Japan): cis-3-hexenyl acetate (catalog \#H2137; >97\%) and cis-3-hexenyl benzoate (catalog \#B1039; >98\%). Except for citronellene, all of these

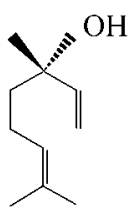

$(+)$

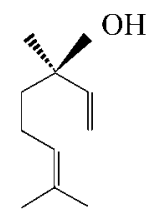

$(-)$

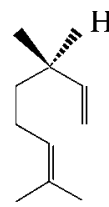

$(+)$

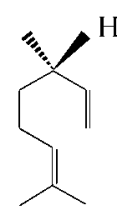

$(-)$ linalool

citronellene

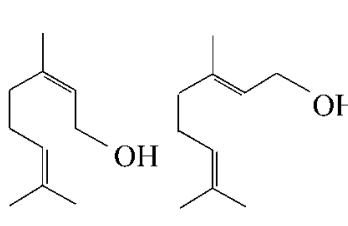

nerol<smiles>C=CC(C)=CCCC(C)C</smiles>

ocimene

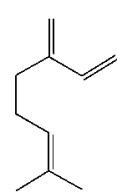

myrcene

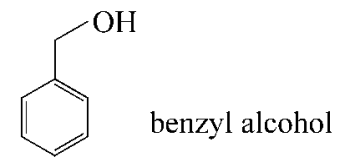<smiles>CCCCCCO</smiles>

hexanol

Figure 1. Chemical structures of some of the odor compounds used in this study. With the exception of citronellene, all are emitted by host plants of Manduca. Odor compounds in the first two rows are monoterpenoids. The pairs of enantiomers of linalool and citronellene appear in the first row. Note that $(+)$ and $(-)$ citronellene are identical to $(+)$ and $(-)$ linalool, respectively, except for the presence of the hydroxyl group at the stereogenic center in linalool. Nerol and geraniol are stereoisomers (cis and trans isomers of 3,7-dimethyl-2,6-octadien-1-ol, respectively). The bottom row shows aromatic and aliphatic alcohols (benzyl alcohol and hexanol, respectively).

compounds are found among the volatiles emitted by host plants of Manduca (Andersen et al., 1988; Loughrin et al., 1990; Fraser et al., 2003). The enantiomeric composition of linalool emitted by those plants has not been reported.

Single odor compounds were diluted in odorless mineral oil (SigmaAldrich; dilutions ranged from 1:10 to 1:10,000 v/v). Fifty microliters of the final dilution were applied to a $25 \mathrm{~mm}$ disk of Whatman no. 1 filter paper and inserted into a capped $20 \mathrm{ml}$ plastic syringe (Norm-Ject; Henke Sass Wolf, Tuttlingen, Germany). The volatile compound was allowed to equilibrate in the syringe for $4 \mathrm{hr}$ at room temperature before use. Control syringes contained $50 \mu \mathrm{l}$ of mineral oil alone. Syringes were stored at $4^{\circ} \mathrm{C}$ until use. At a dilution of 1:1000, the load of odor substance on the filter paper ranged from $38 \mu \mathrm{g}$ for citronellene to $52 \mu \mathrm{g}$ for benzyl alcohol. The concentration of linalool reaching the antenna was calculated on the basis of the actual measurements of the parameters of the relationship between liquid (percentage volume/volume) and vapor phases [parts per million (ppm)] (Cometto-Muñiz et al., 2003). At a dilution of linalool of 1:1000, the concentration of compound reaching the antenna was calculated to be $1.7 \mathrm{ppm}$.

Intracellular recording and staining. Sharp microelectrodes were made from borosilicate glass with filament $(1 \mathrm{~mm}$ o.d., $0.58 \mathrm{~mm}$ i.d.; Sutter Instruments, Novato, CA) on a laser puller (P-2000, Sutter Instruments). The tip of the micropipette was filled with a $3 \%$ solution of Lucifer yellow (Sigma-Aldrich) in $0.2 \mathrm{M} \mathrm{LiCl}$, and the shaft was filled with $2 \mathrm{M} \mathrm{LiCl}$ (electrode resistances ranged from 150 to $350 \mathrm{M} \Omega$ ). The responses of the impaled neuron to stimulation of the ipsilateral antenna were amplified (10× with an Axoclamp-2A; Axon Instruments, Foster City, CA), monitored on an oscilloscope, and digitized at $20 \mathrm{kHz}$ using an interface (Digidata 1200 series Interface, Axon Instruments) and Axoscope software (Axon Instruments). Data were analyzed with custom-made programs written in Matlab (The Mathworks, Natick, MA).

After physiological characterization, neurons were injected with Lucifer yellow by passing hyperpolarizing current $(0.2-0.5 \mathrm{nA})$ for $6-40 \mathrm{~min}$. The duration of intracellular impalements, including both recording and dye injection, was variable (average $=20 \mathrm{~min}$; maximum $=40-50 \mathrm{~min}$ ). 
After completion of an experiment, the brain was excised and immersed in $2.5 \%$ formaldehyde fixative solution, $\mathrm{pH} 7.2$, for at least $3 \mathrm{hr}$, dehydrated through a graded series of ethanol solutions, and cleared with methyl salicylate (Sigma-Aldrich). Cleared brains were imaged as whole mounts (optical sections, $2 \mu \mathrm{m}$ thick) with a laser-scanning confocal microscope (Nikon PCM 2000, equipped with a $457 \mathrm{~nm}$ argon laser). Results were obtained from a total of 36 neurons from 36 animals. Of these, 30 PNs were stained successfully and hence could be characterized morphologically. Thirteen of these morphologically characterized neurons had arborizations in the latLFG glomerulus. Six other neurons could not be positively characterized, but their odor-response profiles indicated that they were latLFG-PNs (see caption to Fig. 7A). Brains were returned to $100 \%$ ethanol and embedded in Spurr's resin (Electron Microscopy Sciences, Ft. Washington, PA) for sectioning at $48 \mu \mathrm{m}$.

For three-dimensional reconstructions, brains with filled cells were rehydrated, immersed overnight in $4 \%$ glutaraldehyde fixative solution, $\mathrm{pH}$ 7.3, dehydrated, cleared, and imaged as whole mounts (optical sections, $0.6 \mu \mathrm{m}$ thick). The borders of the AL, the LFGs, and the glomerulus receiving arborizations of the neuron of interest were reconstructed using Amira software (Konrad-Zuse-Zentrum für Informationstechnik, Berlin, Germany).

Statistics. One- or two-way repeated-measures ANOVAs were performed to test whether the responses of neurons to different odor compounds and concentrations differed statistically. Significant results $(p<$ 0.05) were followed by post hoc Tukey tests (Zar, 1999).

\section{Results}

\section{Responses of latLFG-PNs to enantiomers of linalool}

The LFGs reside near the entrance of the antennal nerve into the $\mathrm{AL}$ and are among the largest glomeruli in female Manduca (Rospars and Hildebrand, 2000). On the basis of their positions and sizes, these glomeruli are easily identifiable. The latLFG lies against the lateral edge of the $\mathrm{AL}$ and slightly anterior to the medLFG (Roche King et al., 2000) (Fig. 2), at a depth of $\sim 200-$ $250 \mu \mathrm{m}$ from the anterior surface of the AL. Three PNs with dense dendritic arborizations restricted to the latLFG are shown in Figure 2C-E. As reported previously (Roche King et al., 2000), these neurons had their somata in the medial group of ALneuronal cell bodies and an axon projecting from the AL, through the inner antennocerebral tract, to higher brain centers, including the calyces of the ipsilateral mushroom body and the lateral protocerebrum (Fig. $2 F$ ). The 13 latLFG-PNs (each obtained from a different animal) described in this study shared this same basic morphology and were classified as type PIa neurons (Homberg et al., 1988; Roche King et al., 2000).

Intracellular recordings obtained from morphologically characterized latLFG-PNs showed that these neurons responded more sensitively to antennal stimulation with $(+)$ linalool than with (-)linalool (Fig. 3). The responses to both enantiomeric forms of linalool grew stronger with increasing concentrations (Fig. 3). Twelve morphologically characterized latLFG-PNs, obtained from 12 different animals, were tested with $(+)$ and $(-)$ linalool at a 1:1000 dilution. The response to the $(+)$ enantiomer (net number of spikes) was much stronger than the response to the $(-$ ) enantiomer (one-way repeated-measures ANOVA: $\mathrm{df}=$ 2,22; $F=90.78 ; p<0.00001$; Tukey test: $p=0.00014)$. The net number of spikes evoked by stimulation with $(+)$ and $(-)$ linalool were $16 \pm 1.5$ and $3.6 \pm 1.2$, respectively (means \pm SEM; $n=$ 12). In some cases $(-)$ linalool failed to evoke a response (Figs. 3 , 4, PNs 1, 6, 7 and 10). Moreover, the response to the (+) enantiomer was statistically more different from the blank than the response to the $(-)$ enantiomer (Tukey tests: $p=0.00014$ and $p=0.025$, respectively).

The odor-response profiles of the 13 latLFG-PNs examined in this study were qualitatively consistent from animal to animal: in
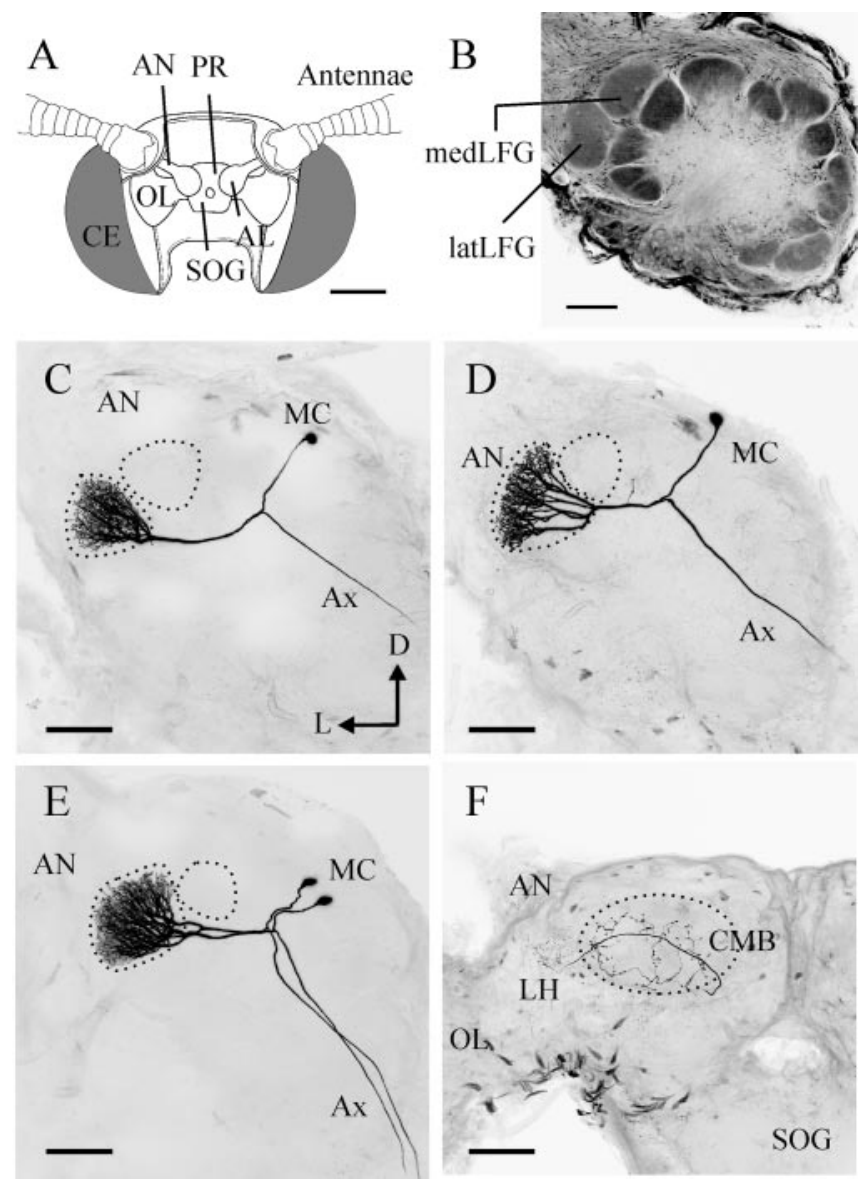

$\mathrm{F}$

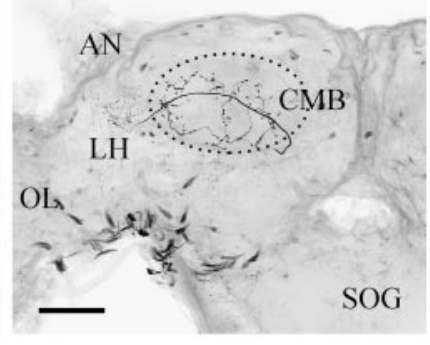

Figure 2. A, Schematic frontal view of the head of Manduca. Each primary olfactory center, the antennal lobe $(\mathrm{AL})$, receives input from olfactory receptor cells in the ipsilateral antenna via axons projecting through the antennal nerve (AN). The output neurons of the AL, the projection neurons (PNs), extend axons to the protocerebrum (PR). CE, Compound eye; OL, optic lobe; SOG, suboesophageal ganglion. Scale bar, $1 \mathrm{~mm}$. $B$, Confocal microscopic image of a female AL showing the positions of two sexually dimorphic glomeruli, the large female glomeruli (LFGs). The lateral LFG (latLFG) and the medial LFG (medLFG) reside at the entrance of the AN into the AL. Scale bar, $100 \mu \mathrm{m}$. (-E, Examples of AL PNs from this study with arborizations confined to the latLFG. All latLFG-PNs have a soma in the medial group of neuronal cell bodies (MC) and an axon $(\mathrm{Ax})$ projecting into the protocerebrum from the AL. Dotted lines represent the outlines of the latLFG and medLFG. F, Axon collaterals of the PN shown in D, branching in the calyces of the ipsilateral mushroom body (CMB) (dotted lines) and the lateral horn ( $\mathrm{LH}$ ) of the protocerebrum. Scale bars: $(-E, 100 \mu \mathrm{m} ; F, 200 \mu \mathrm{m}$. D, Dorsal; L, lateral.

all cases, $(+)$ linalool evoked a stronger response than $(-)$ linalool that was stimulus-locked to the odor pulse. Individual PNs, however, differed in their sensitivity to linalool, as indicated by the variation in instantaneous spike frequency (ISF) evoked by antennal stimulation with this compound (Fig. 4).

The primary response of latLFG-PNs to antennal stimulation with linalool consisted of an excitatory phase with spiking, followed by an inhibitory phase characterized by membrane hyperpolarization and suppression of spiking (Fig. 3). Figure 5 shows a quantitative analysis of the physiological response properties of eight latLFG-PNs (one per animal) that could be tested with $(-)$ linalool and $(+)$ linalool at two concentrations $(1: 100$ and $1: 1000, \mathrm{v} / \mathrm{v})$. At both concentrations, stimulation with $(+)$ linalool evoked a statistically greater number of spikes, greater peak and summed instantaneous spike frequencies, and more prolonged excitatory and inhibitory phases than did stimulation with (-)linalool (two-way repeated-measures ANOVAs: in all cases, $p<0.005$ ) (Fig. 5). The delay to the onset of the excitatory 
(+)linalool 1:1,000

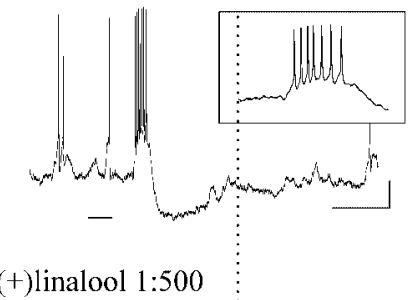

$(+)$ linalool 1:500

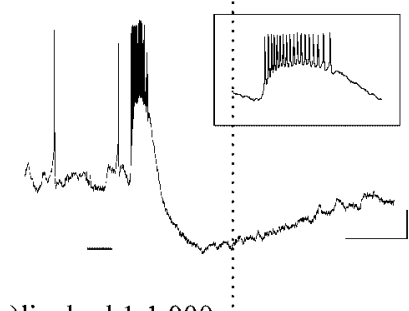

(-)linalool 1:1,000

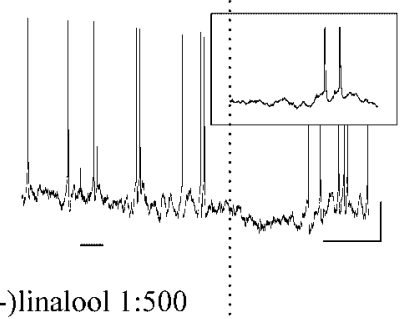

(-)linalool 1:500

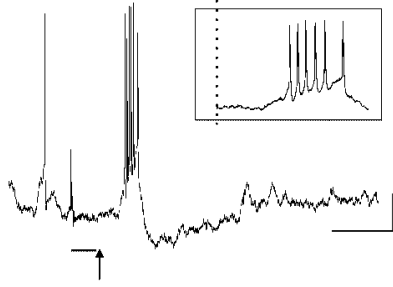

blank

ocimene $1: 10$

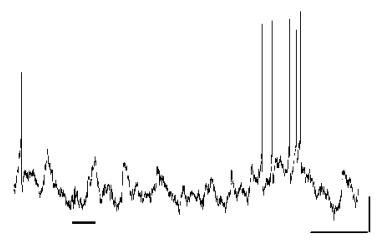

$(+)$ citronellene $1: 10$

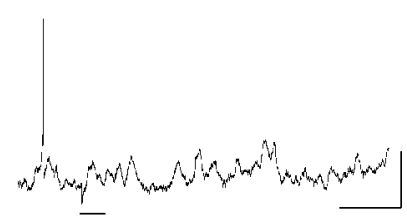

(-)citronellene 1:10

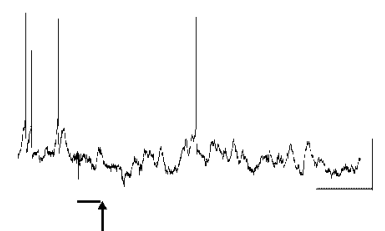

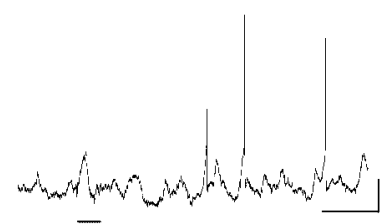

Figure 3. Intracellular recordings obtained from the latLFG-PN shown in Figure 2C. This projection neuron was tested by antennal stimulation with the odor compounds and concentrations indicated (v/v). Stimulus onset and duration ( $200 \mathrm{msec}$ ) are indicated by the solid line below each record. The arrows indicate the arrival of the stimulus to the antenna (calculated from the EAG responses). At 1:1000, (-)linalool evoked no response. The response to (+)linalool was stronger than the response to ( - )linalool and was dose dependent. Ocimene and both enantiomers of citronellene evoked no response even when tested at high concentrations. Insets show 300 msec segments on an expanded time scale. The vertical line serves as a time reference for those insets. Calibration: $5 \mathrm{mV}, 500 \mathrm{msec}$.

phase of the response was significantly shorter when $(+)$ linalool was used as the stimulus (two-way repeated-measures ANOVA: $p<0.005$ ) (Fig. 5). For both enantiomers of linalool, we observed a significant increase in the intensity of all response parameters (in the case of the onset delay, a decreased latency) with increasing stimulus concentration (two-way repeated-measures ANOVAs: in all cases, $p<0.01$ ) (Fig. 5).

To examine more thoroughly the relationship between PN enantioselectivity and stimulus concentration, five latLFG-PNs (each from a different animal) were tested with a wider range of stimulus dilutions from 1:10,000-1:100. In all neurons, and at all concentrations tested, $(+)$ linalool evoked a stronger response than did (-)linalool (Fig. 6). We next asked what structural features of $(+)$ linalool are necessary to evoke a response from latLFG-PNs. We stimulated nine $(+)$ linalool-selective neurons with $(+)$ citronellene and $(-)$ citronellene, an odor compound identical to linalool except for the absence of the hydroxyl group linked to the stereogenic center at the third carbon (Fig. 1). Even at elevated concentrations, both enantiomers of citronellene failed to evoke responses from these neurons (Figs. 3, 7A). Figure $7 B$ shows an example of responses of a latLFG-PN to antennal stimulation with different concentrations of several volatiles, all of which except citronellene are emitted by host plants of Manduca. Although structurally similar to linalool, the monoterpenoids citronellene, ocimene, myrcene, and geraniol did not evoke a response from this PN. In contrast, both nerol (a stereoisomer of geraniol) and hexanol evoked excitatory responses, but only when presented at the highest, probably nonphysiological, concentration (1:10). At that concentration, benzyl alcohol evoked a few spikes. In another latLFG-PN, 2-octanol also evoked an excitatory response at the 1:10 concentration, but the corresponding ketone, 2-octanone, did not (data not shown). The selectivity for $(+)$ linalool, among the compounds in the test panel, was observed in seven latLFG-PNs (several neurons could be tested with only a subset of odor compounds and concentrations). These results also indicate that the presence and position of the hydroxyl group in the linalool molecule are key determinants for activating the inputs to latLFG-PNs.

\section{PNs preferentially responsive to $(-)$ linalool}

In contrast to the latLFG-PNs, which responded preferentially to the $(+)$ enantiomer of linalool, we also recorded from five PNs (one per animal) that preferred $(-)$ linalool over $(+)$ linalool (Figs. 8, 10A). In four animals, $(+)$ linalool failed to evoke a response from these PNs. These enantioselective PNs had arborizations confined to a glomerulus adjacent to the latLFG [glomerulus no. 15 described by Rospars and Hildebrand (2000)], a cell body in the lateral group of AL-neuronal cell bodies, and an axon projecting from the AL to the calyces of the ipsilateral mushroom body and the lateral horn of the protocerebrum (Fig. 8). The relative position of the LFGs and of the glomerulus housing the arborizations of the $(-)$ linalool-responsive PNs are shown in the reconstruction in Figure 9.

Although they could discriminate the two enantiomeric forms of linalool, these PNs were less sensitive to $(-)$ linalool than the latLFG-PNs were to $(+)$ linalool. This suggests that a structurally related compound, but not $(-)$ linalool itself, might be the optimal stimulus for these PNs. We analyzed the structural features of ( - ) linalool that were needed to evoke responses from these PNs. Antennal stimulation with compounds lacking the hydroxyl group, such as $(-)$ citronellene, $(+)$ citronellene, myrcene, and ocimene, evoked no response (Fig. $10 \mathrm{~B}$ ). The monoterpene alcohol geraniol evoked an excitatory response [slightly more effectively than (-)linalool], whereas nerol (its stereoisomer) did not (Fig. $10 \mathrm{~B}$ ). Antennal stimulation with another monoterpene alcohol, citronellol, also excited this neuron (data not shown). Among the nonmonoterpene alcohols, only hexanol evoked a response, but at very high concentrations (Fig. 10B). The terpenoid ketone geranyl acetone and the ester cis-3-hexenyl acetate evoked responses only at a 1:10 dilution, whereas cis-3-hexenyl benzoate did not produce a response (data not shown). This odor-response profile was observed in at least two other ( - ) linalool-sensitive PNs, although not all odor compounds and concentrations could be tested. Thus, as observed for latLFGPNs, the presence of the hydroxyl group in a particular position in the linalool molecule is important for stimulating the inputs to these enantioselective PNs. 
Neuron \#

blank

(-) linalool

$(+)$ linalool

1

2

3

4

6

7

$8 \quad 1$

9

10

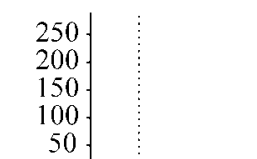

250
200
150
100
50
0

250
200
150
100

250
200
150
150

(250
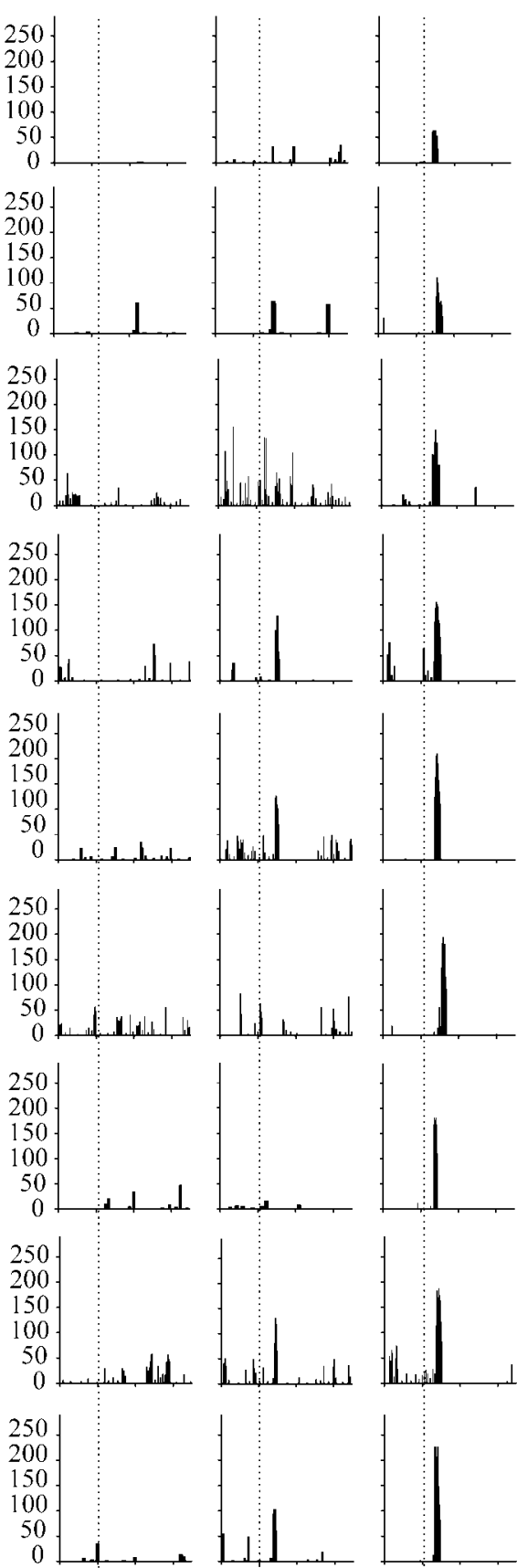

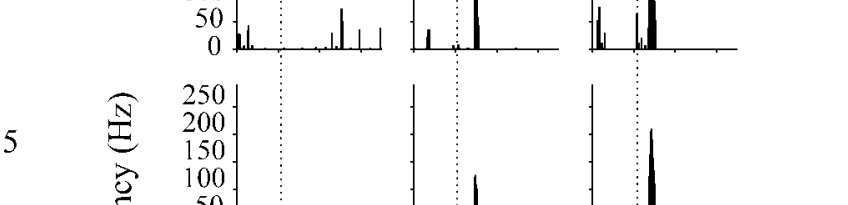
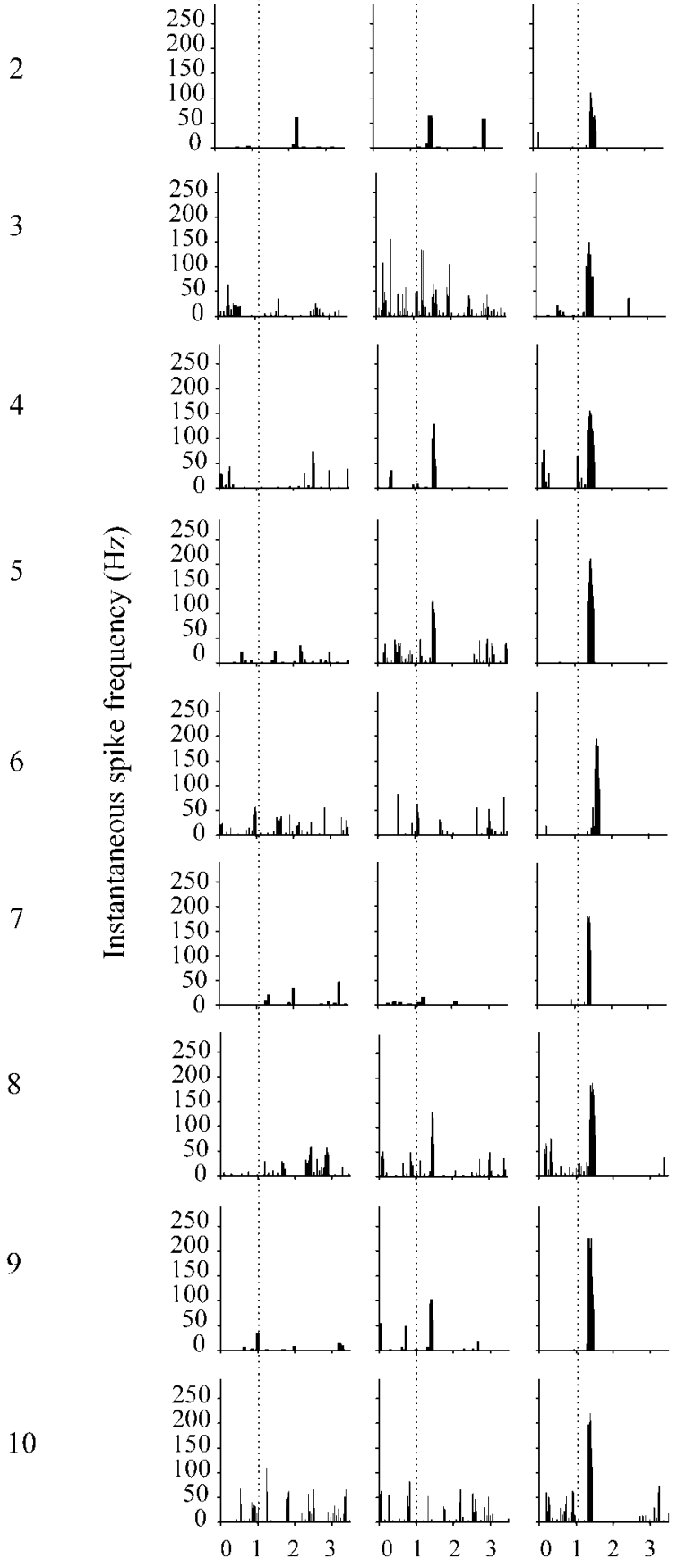

Time (seconds)

Figure 4. Plots of instantaneous spike frequency versus time for 10 of the latLFG-PNs included in this study (of a total of 13 latLFG-PNs, all sharing the same enantioselectivity). Representative responses of each projection neuron to antennal stimulation with the mineral oil blank and $(-)$ linalool and $(+)$ linalool at a concentration of 1:1000 are shown. The onset of the 200 msec stimulus is indicated by the vertical dotted line in each column. All latLFG-PNs showed a higher instantaneous spike frequency when the ipsilateral antenna was stimulated with $(+)$ linalool than when it was stimulated with (-)linalool. In several cases (PNs 1, 6, 7, and 10), (-)linalool failed to evoke a response. PNs were numbered in order of ascending peak instantaneous spike frequency.
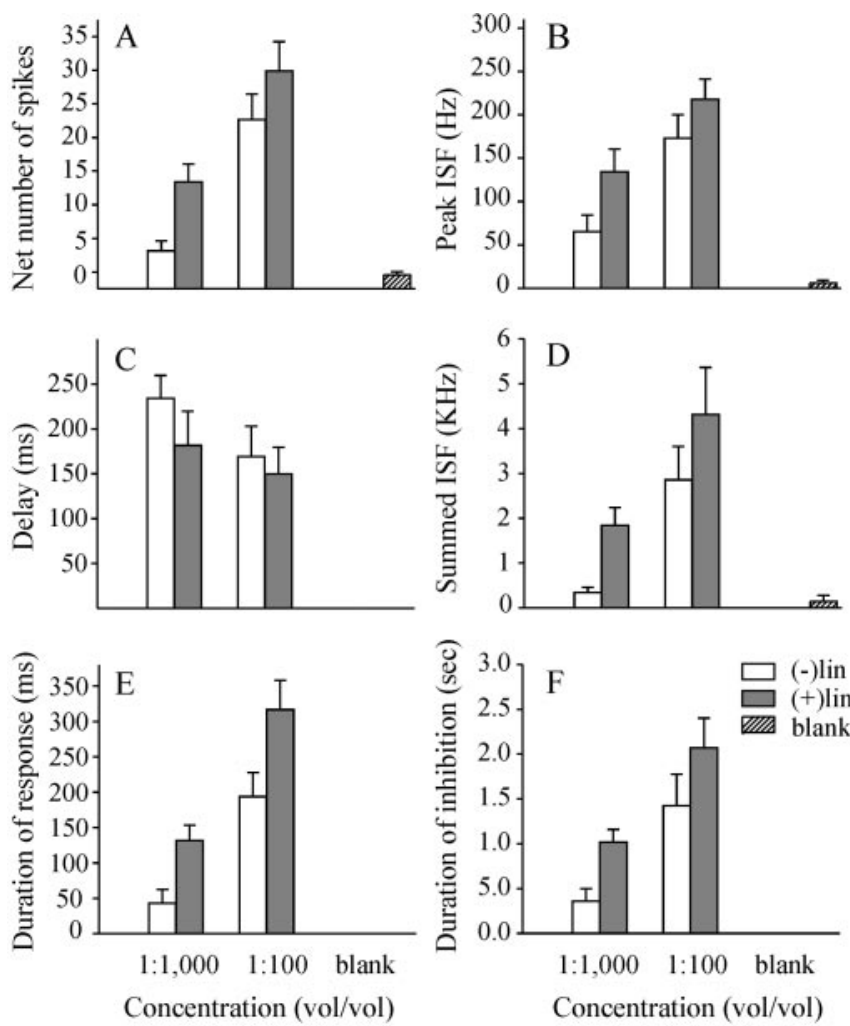

Figure 5. Responses of latLFG-PNs (grouped data). Eight morphologically characterized latLFG-PNs, each from a different animal, were tested with one to four presentations of two concentrations of $(-)$ and $(+)$ linalool and the mineral oil blank. Averages were calculated for each neuron, odor compound, and concentration. Data are represented as means \pm SEM ( $n=$ 8 in all panels except $C$. $A$, The net number of spikes during the excitatory phase of the response (the mean number of spikes during the prestimulation period was subtracted); $B$, the peak ISF measured during the excitatory phase of the response; $C$, the delay, calculated as the time elapsed between the arrival of the odor stimulus to the antenna (calculated from the EAG responses) and the first spike evoked by the odor stimulation; $D$, the sum of the ISF during the excitatory period of the response; $E$, the duration of the excitatory response (time elapsed between the first spike and the last spike evoked by the odor stimulation); $F$, the duration of the inhibitory phase of the response (time elapsed from the end of the excitatory response to the return of background activity). Because some neurons did not respond to all concentrations and enantiomeric forms of linalool, statistics about the delay $(C)$ were calculated for five of the eight neurons tested. $(+)$ lin, $(+)$ linalool; $(-)$ lin, $(-)$ linalool. In all cases, responses to $(+)$ linalool were statistically different from responses to $(-)$ linalool (two-way repeated-measures AN0VAs: in all cases, $p<0.005)$. The response to both enantiomeric forms of linalool increased with concentration (two-way repeated-measures ANOVAs: in all cases, $p<0.01$ ). Interactions between factors were not statistically significant (in all cases, $p>0.05$ ). df $=1,7$ (in $C$, df $=1,4$ ).

\section{Neurons that do not discriminate between enantiomers of linalool}

Figure 11, $A$ and $B$, shows confocal microscopic images of two PNs that responded equally well to antennal stimulation with either enantiomer of linalool. In this study we recorded from 12 such PNs. All of them had arborizations restricted to glomeruli situated in the vicinity of the latLFG, but none was associated with the latLFG itself. Eleven of these PNs had cell bodies in the lateral group of AL-neuronal cell bodies, and one had cell bodies in the medial cell group. Two of these neurons had arborizations restricted to the same glomerulus, the so-called anterodorsal glomerulus (ADG) (Roche King and Hildebrand, 1999); one is shown in Figure $11 B$.

Figure $11 C$ shows the physiological responses of a PN to stimulation with $(-)$ linalool and $(+)$ linalool. Some PNs responded to antennal stimulation with low concentrations of linalool (Fig. 


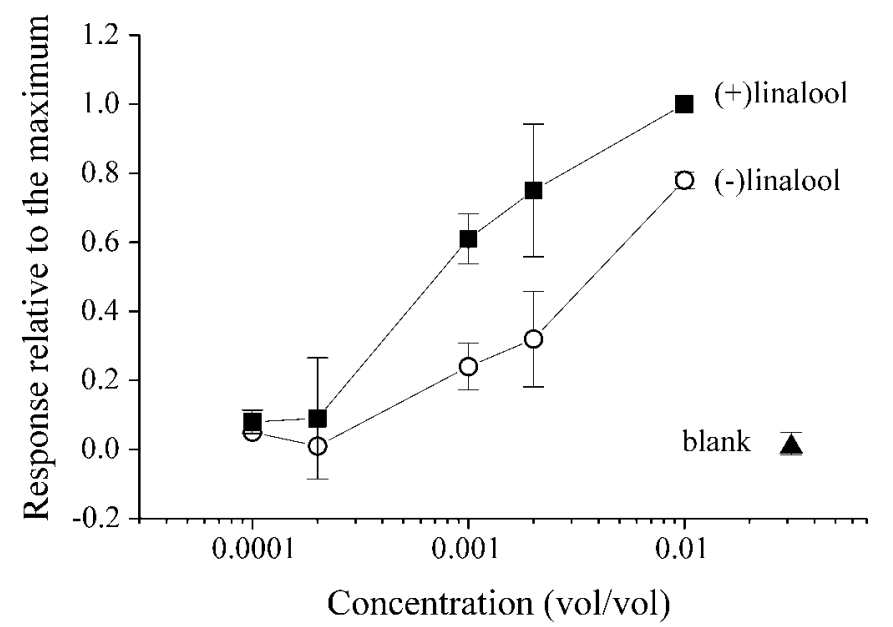

Figure 6. Dose-response profiles of latLFG-PNs (grouped data, mean \pm SEM), constructed by plotting the net number of spikes (relative to the maximum) as a function of concentration (log scale) of the stimulus compounds, $(-)$ and $(+)$ linalool ( $\bigcirc$ and $\mathbf{\square}$, respectively); $\mathbf{\Delta}$ indicates responses to the mineral oil blank. Recordings were obtained from five neurons from five different animals. Four neurons were morphologically characterized as latLFG-PNs (one is shown in Fig. 2E); the fifth neuron was not stained intracellularly and therefore could not be characterized morphologically, but its odor-response profile indicates that it was a latLFG-PN. In all five cases, $(+)$ linalool evoked a stronger response than $(-)$ linalool across the range of concentrations tested. Different neurons, however, exhibited different sensitivities to linalool [the net number of spikes evoked by stimulation with (+)linalool at the highest concentration ranged from 29 to 44 (average $=37 ; n=5$ )]. Not all neurons were tested with the five concentrations plotted, but all were tested with at least three: the highest concentration $(1: 100)$, one of the lowest $(1: 10,000$ or $1: 5000)$, and one concentration in the middle of the range (1:1000).

$11 D)$, whereas others responded only to stimulation with higher concentrations (Fig. $11 E$ ). At both concentrations, the responses to $(-)$ linalool and $(+)$ linalool, measured as the net number of spikes evoked by odor stimulation, were not significantly different [one-way repeated-measures ANOVAs followed by Tukey tests: responses to $(+)$ and $(-)$ linalool were different from the blank $(p<0.005)$ but not from each other $(p>0.05)]$ (Fig. $11 D, E)$.

To test which structural features of linalool were required by these PNs, we tested some of these neurons with the odor compounds shown in Figure 1. Figure $11 C$ shows an example of a neuron that responded equally well to stimulation with $(-)$ linalool and $(+)$ linalool, $(-)$ citronellene, $(+)$ citronellene, geraniol, nerol, ocimene, and myrcene (responses to the last three odor compounds are not shown). This PN did not respond to stimulation with the nonterpenoid alcohols hexanol and benzyl alcohol. In contrast, PNs with arborizations in the ADG (Fig. 11B) did not respond to stimulation with odor compounds lacking a hydroxyl group (data not shown). Thus, in the first example, it appeared that neither the alcohol functional group nor the absolute configuration of the molecule was a critical determinant for evoking the response. In the second example, the presence of the functional group in a particular arrangement seemed to be necessary. Furthermore, we found that some of these nonenantioselective PNs might be tuned not to linalool but to other, related monoterpenoids. For example, another PN responded equally well to both enantiomers of linalool but gave a stronger response when tested with even lower concentrations of geraniol (but not with its stereoisomer, nerol; data not shown). These results suggest that other structural features of linalool, besides its stereogenic center, are important in determining the response in these non-enantioselective PNs.
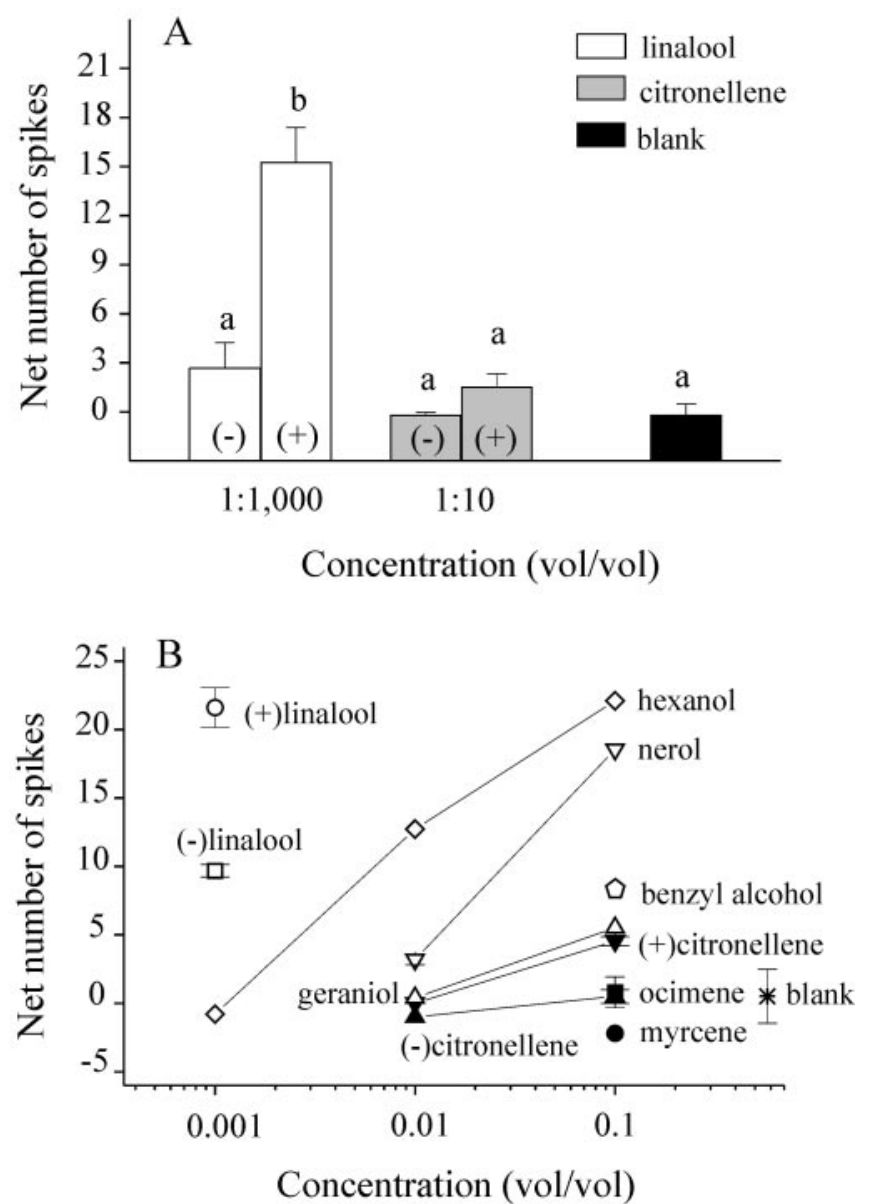

Figure 7. Structural features of $(+)$ linalool required for the excitatory response of latLFGPNs. $A$, Response (net number of spikes, mean \pm SEM) of nine neurons when stimulated with $(-)$ and $(+)$ linalool at a concentration of 1:1000 (open bars), $(+)$ and $(-)$ citronellene at a concentration of 1:10 (gray bars), and the mineral oil blank (black bar). In the bars, $(-)$ and $(+)$ indicate the enantiomers of the stimulus compounds. Each of the nine neurons was more sensitive to $(+)$ than to $(-)$ linalool. Both $(+)$ and $(-)$ citronellene, although tested at a concentration 100 times higher than linalool, failed to evoke a response. Note that the only difference between linalool and citronellene is the presence of the hydroxyl group in linalool (Fig. 1). Four of the neurons were morphologically characterized as latLFG-PNs. The remaining five neurons could not be characterized morphologically with confidence, but their odorresponse profiles were consistent with their being latLFG-PNs. Means coded by different lowercase letters differ significantly (repeated-measures ANOVA: $\mathrm{df}=4,32 ; F=48.39 ; p<$ 0.000001 ; followed by post hoc Tukey tests: $p<0.0005$ ). Means coded by same lowercase letters do not differ statistically (Tukey tests: $p>0.05$ ). $B$, Net number of spikes as function of concentration for a morphologically characterized latLFG-PN stimulated with both enantiomers of linalool and citronellene and with geraniol, nerol, hexanol, myrcene, ocimene, and benzyl alcohol. Open and closed symbols indicate alcoholic and nonalcoholic compounds, respectively. $(+)$ Linalool evoked the strongest response from this PN; the alcohols hexanol and nerol elicited excitatory responses but at a much higher concentration. Geraniol (a stereoisomer of nerol) and benzyl alcohol elicited very weak responses at the highest concentration tested (1:10). At that high concentration, the monoterpenoids myrcene, ocimene, and $(-)$ citronellene were not effective, whereas $(+)$ citronellene evoked a few spikes. Data points represent averages of one to four stimulus trials. Altogether, these results suggest that the presence of the hydroxyl group, in a particular configuration, is necessary to evoke a response from latLFG-PNs.

\section{Discussion}

We analyzed the enantioselectivity of specific olfactory glomeruli by intracellular recording from and staining of individual PNs (output) in the AL of female Manduca. We focused on linalool, a chiral volatile emitted by plants, including the host plants of Manduca, and found (1) that latLFG-PNs are significantly more responsive to antennal stimulation with $(+)$ linalool than with 

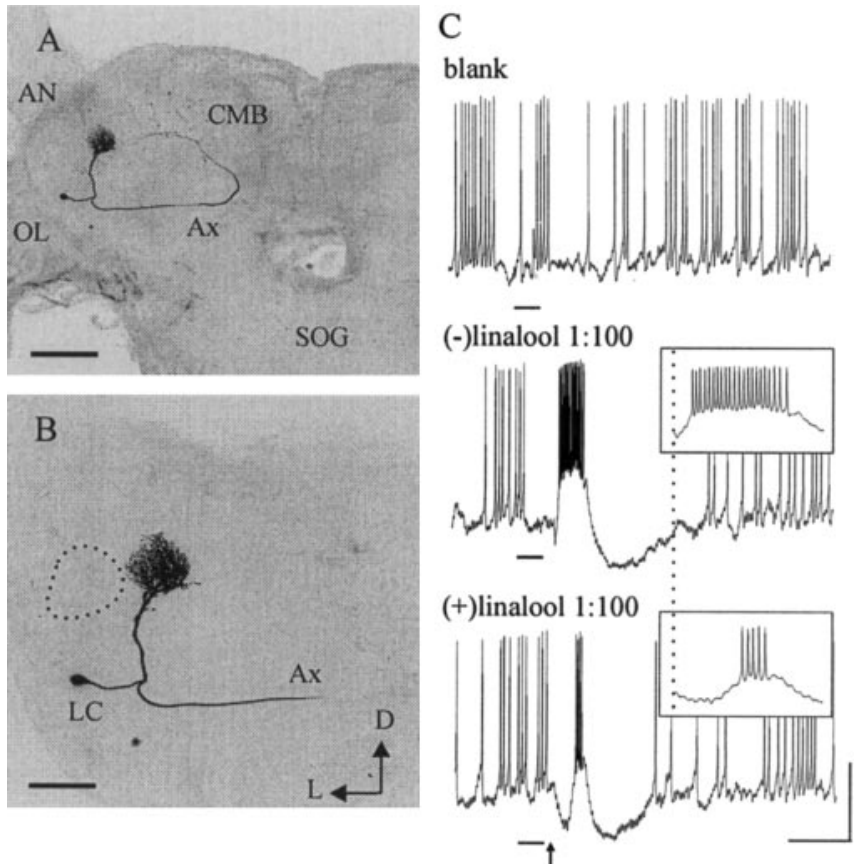

Figure 8. Morphological and physiological properties of a PN more responsive to (-)linalool than to $(+)$ linalool. $A$, Confocal stack collected from a whole-mount preparation. This projection neuron had its soma in the lateral group of $A L$ neurons $(\mathrm{LC})$ and an axon (Ax) projecting from the AL to the calyces of the ipsilateral mushroom body (CMB) and the lateral protocerebrum (LH). OL, Optic lobe. Scale bar, $200 \mu \mathrm{m}$. B, Higher-magnification confocal microscopic image of the preparation shown in $A$. The arborizations of this $\mathrm{PN}$ were restricted to glomerulus 15 [described by Rospars and Hildebrand (2000)], adjacent to the latLFG (which is indicated by the dotted lines). Scale bar, $100 \mu \mathrm{m}$. C, Intracellular recordings from this PN in response to stimulation with the mineral oil blank and $(-)$ linalool and $(+)$ linalool at a concentration of 1:100. Stimulus (duration $=200 \mathrm{msec}$ ) onset is indicated by the solid line below each record. The arrow indicates the arrival of the stimulus at the antenna (calculated from the EAG responses). Insets show a $300 \mathrm{msec}$ segment on an expanded time scale. The vertical line serves as a time reference for those insets. Calibration: $10 \mathrm{mV}, 500 \mathrm{msec}$.

(-)linalool, (2) that PNs with arborizations in a glomerulus adjacent to the latLFG are more responsive to $(-)$ linalool, and (3) that PNs innervating other glomeruli in the vicinity of the latLFG cannot discriminate between the two enantiomers of linalool. Structure-activity studies revealed that the presence of the hydroxyl group in the linalool molecule is a key determinant for activating the inputs to these enantioselective PNs. Although a small number of odorous molecules were tested, our results suggest that the molecular receptive range (Mori et al., 1992) of a glomerulus can be limited to few structurally related odor compounds, including enantiomers.

Without exception, all 13 latLFG-PNs examined in this study were more responsive to $(+)$ linalool than to $(-)$ linalool. In these neurons, antennal stimulation with $(+)$ linalool consistently evoked a greater instantaneous spike frequency, a greater number of spikes, longer excitatory and inhibitory phases, and a shorter delay to onset of the excitatory response than stimulation with (-) linalool (Figs. 3-5). These effects were dose dependent, i.e., the response increased with increasing concentration of the odor stimulus (Figs. 5, 6). We found that PNs innervating a glomerulus adjacent to the latLFG responded much better to $(-)$ linalool than to $(+)$ linalool (Figs. 8, 10). Our observations indicate that this was the glomerulus 15 described by Rospars and Hildebrand (2000) (Fig. 9). Finally, we found a group of 12 PNs with arborizations in sexually isomorphic glomeruli, mostly in the vicinity of the latLFG, that responded equally well to stimulation of the
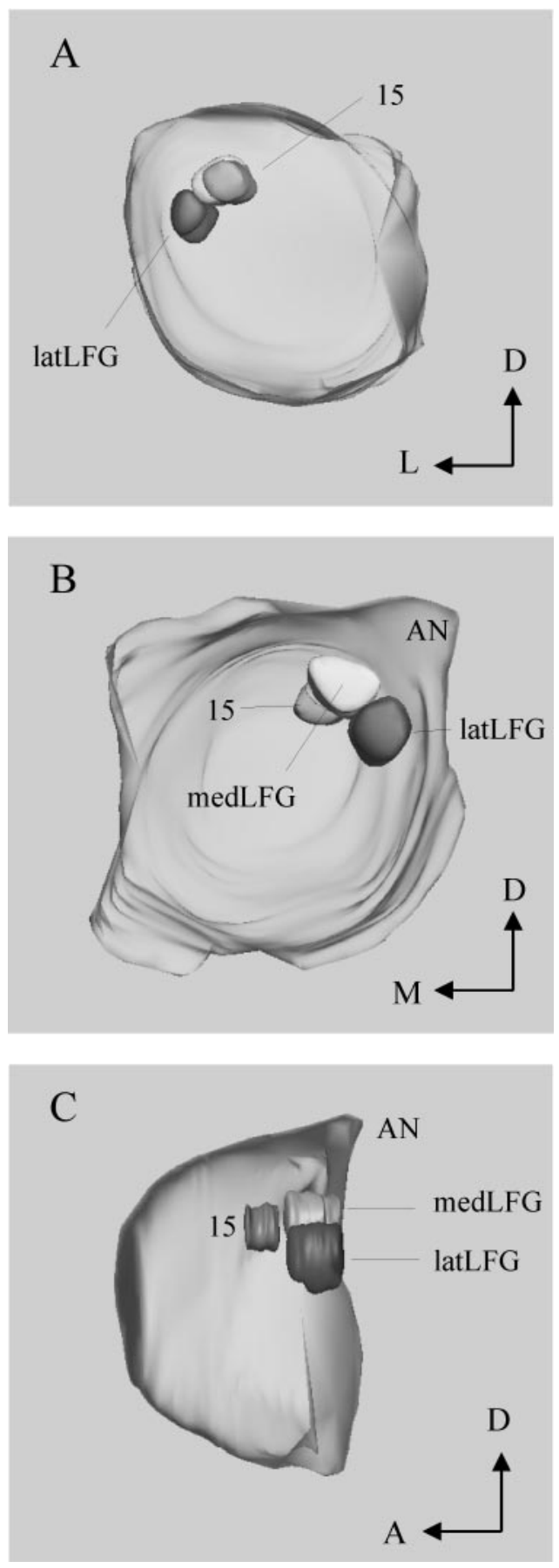

Figure 9. Reconstruction of a female AL showing the positions of the latLFG, the medLFG, and glomerulus 15 from three different perspectives $(A$, anterior view; $B$, posterior view; $C$, antennal nerve view). D, Dorsal; L, lateral; $M$, medial; $A$, anterior.

antenna with either $(-)$ linalool or $(+)$ linalool (Fig. 11). Our observation that $\mathrm{PNs}$ innervating glomeruli in close proximity to one another have complementary response profiles underscores the importance of studying individual neurons associated with identifiable glomeruli.

Our findings are in line with investigations in diverse species confirming that glomeruli are functional units dedicated to synaptic processing of primary-afferent information about a particular odor compound, related compounds, or a certain molecular attribute(s) of the odor compound(s). Most of these studies, which are based on imaging using various different activity mark- 

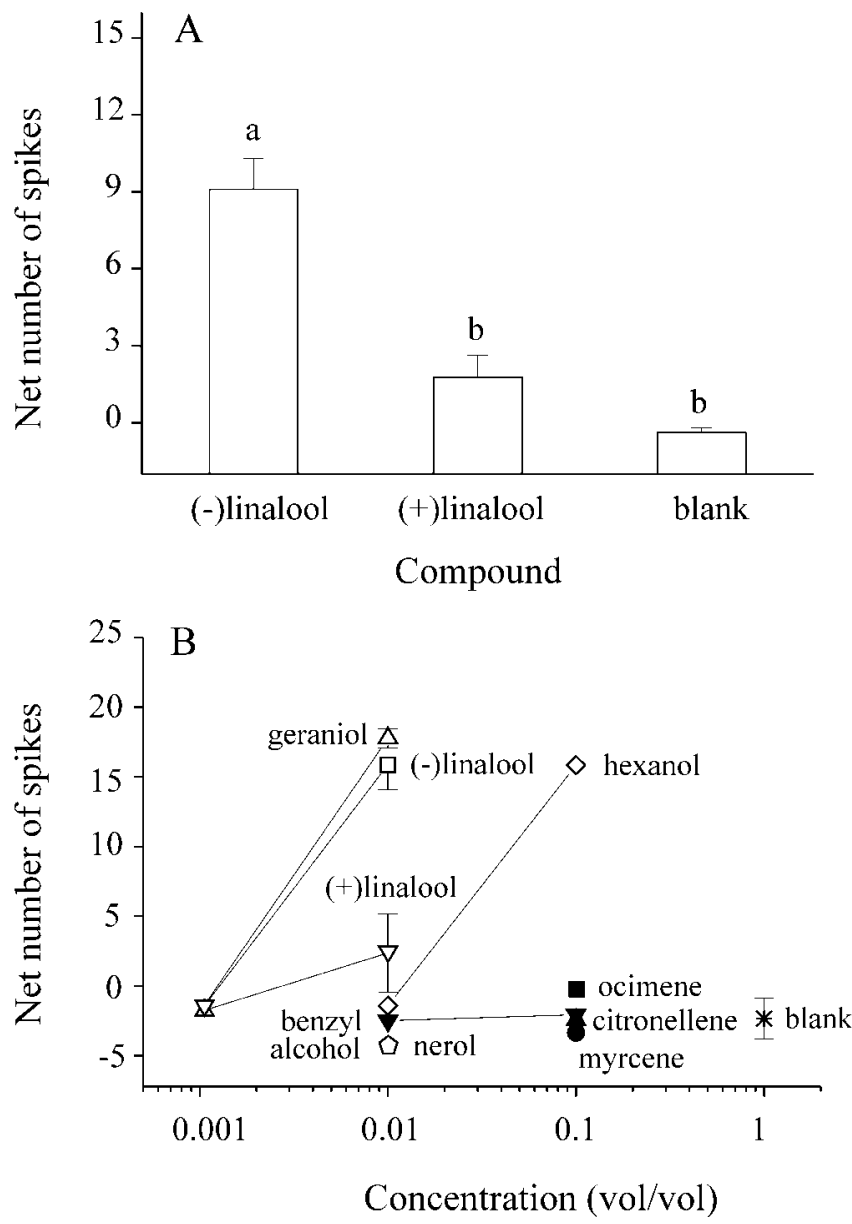

Figure 10. Responses of morphologically characterized projection neurons that were more responsive to $(-)$ linalool than to the $(+)$ enantiomer. $A$, Net number of spikes (mean \pm SEM; $n=5$ ) evoked by stimulation with $(-)$ and $(+)$ linalool, at a 1:100 concentration, and the mineral oil blank. All PNs had arborizations confined to glomerulus 15 [described by Rospars and Hildebrand (2000)], adjacent to the latLFG. Means coded by different lowercase letters differ significantly. The response to $(-)$ linalool was statistically different from the responses to the blank and $(+)$ )linalool [repeated-measures ANOVA ( $\mathrm{df}=2,8 ; F=12.67 ; \mathrm{p}<0.005$ ) followed by Tukey tests $(p<0.015$ and $p<0.005$, respectively)]. The response to ( + )linalool was not statistically different from the blank (Tukey test: $p>0.05$ ). $B$, Net number of spikes as a function of concentration (mean \pm SEM; average of $1-5$ trials) for a $(-$ )linalool-sensitive PN when stimulated with both enantiomeric forms of linalool and citronellene as well as nerol, geraniol, myrcene, ocimene, hexanol, benzyl alcohol, and the mineral oil blank. Open and closed symbols indicate alcohol and nonalcohol odor compounds, respectively. Stimulation with volatiles lacking the alcohol group failed to evoke a response. Note that the monoterpenoid alcohol geraniol evoked an excitatory response, slightly stronger than that elicited by (-)linalool, whereas its stereoisomer, nerol, did not. The morphology of this neuron is shown in Figure $8, A$ and $B$. Altogether, these results suggest that the presence of the hydroxyl group in a particular position in the linalool molecule is a key determinant in triggering responses in these enantioselective PNs.

ers, have revealed that odor compounds evoke spatially organized combinatorial patterns of neural activity in the vertebrate olfactory bulb (Mombaerts et al., 1996; Friedrich and Korsching, 1998; Rubin and Katz, 1999; Belluscio and Katz, 2001) and the insect AL (Joerges et al., 1997; Carlsson et al., 2002; Hansson et al., 2003). These patterns are dose dependent, i.e., they are sparse at low concentrations and become denser and less odor specific at high concentrations (Friedrich and Korsching, 1997; Rubin and Katz, 1999; Wachowiak and Cohen, 2001, 2003; Ng et al., 2002; Wang et al., 2003). In most cases, however, the types of cells responsible for the imaged patterns are not known [but see $\mathrm{Ma}$
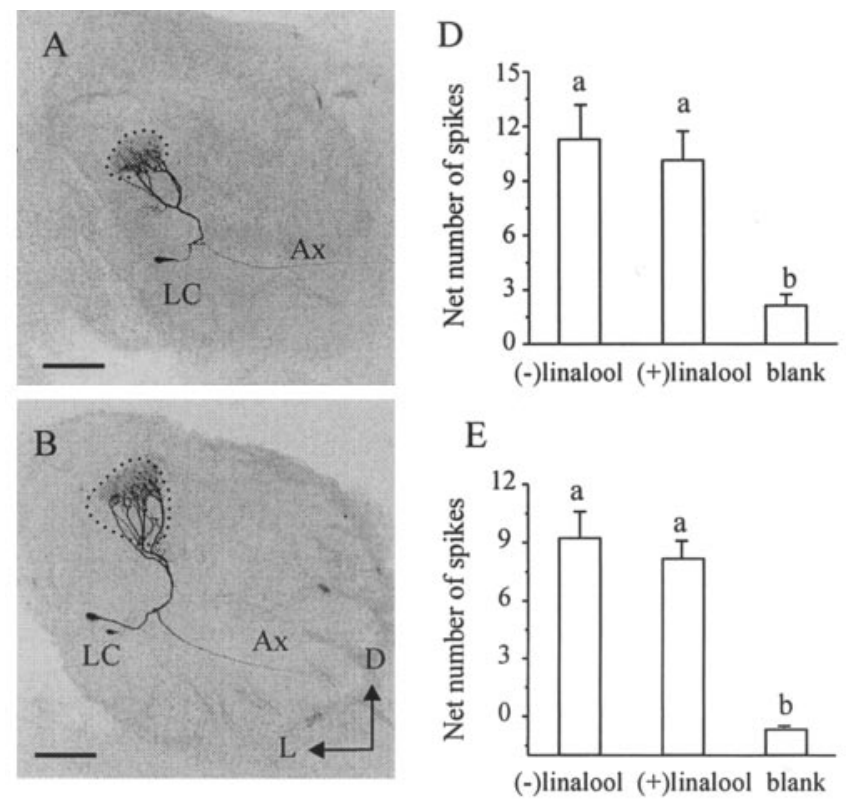

\section{C}

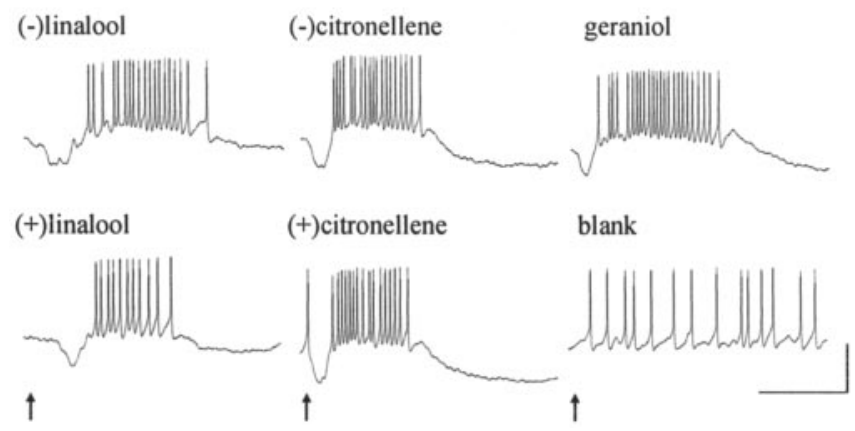

Figure 11. Projection neurons similarly responsive to the two enantiomers of linalool. $A, B$, Two examples of non-enantioselective PNs (a total of 12 were morphologically characterized in 12 different animals). Non-enantioselective PNs had arborizations restricted to glomerulus in the vicinity of the lat $L F G$ and glomerulus 15 , and extended an axon (Ax) into the protocerebrum. Dotted lines represent the outlines of the glomeruli housing the arborizations of these PNs. Images are confocal stacks collected from whole-mount preparations. Scale bars, $100 \mu \mathrm{m}$. D, Dorsal; L, lateral. C, Responses of a morphologically characterized, non-enantioselective PN. This neuron was stimulated with the odor compounds shown in this figure, and also with nerol, ocimene, myrcene, benzyl alcohol, and hexanol. All volatiles were presented at a concentration of 1:100. The arrows indicate the arrival of the stimulus at the antenna (calculated from the EAG responses). This neuron responded to stimulation with all odor compounds except the nonterpenoids hexanol and benzyl alcohol. Calibration: $2.5 \mathrm{mV}, 400 \mathrm{msec}$. D, E, Net number of spikes (mean \pm SEM) evoked by stimulation with $(-)$ and $(+)$ linalool at a concentration of 1:1000 (D) or 1:100 (E). Data were obtained from 12 different PNs $(n=5$ in $A ; n=7$ in $B)$. Means coded by different lowercase letters differ significantly. Responses to $(-)$ and $(+)$ linalool were statistically different from the blank [repeated-measures ANOVAs: in $D, \mathrm{df}=2,8 ; F=28.17 ; p<$ 0.0005; post hoc Tukey tests significant at the 0.01 level. In $E, d f=2,12 ; F=46.25 ; p<$ 0.000005 ; post hoc Tukey tests significant at the 0.0005 level]. Responses to $(-)$ and ( + )linalool were not statistically different from each other (Tukey tests: $p>0.05$ ).

and Shepherd (2000), Wachowiak and Cohen (2003), and references below], making it difficult to draw conclusions about the functional significance of imaged activity patterns.

The importance of probing the cells underlying glomerular activity patterns is evident in previous work. In Drosophila, two studies reported that similar glomerular activity patterns emerge from imaging either ORCs or PNs (Ng et al., 2002; Wang et al., 2003, while using intracellular recording techniques, Wilson et al. (2004) showed that local interneurons drastically alter these patterns. In honey bees, AL circuitry transforms antennal inputs into 
a more restricted glomerular pattern of activated PNs (Sachse and Galizia, 2002, 2003). In moths, the responses of male-specific PNs are shaped by inhibitory interglomerular interactions that fine-tune glomerular output (Vickers et al., 1998; Lei et al., 2002).

The present study illustrates the utility, in studies of glomerular function, of using odor stimuli that are biologically relevant and presented at naturally occurring concentrations, as well as the importance of correlating odor-response profiles with morphologically characterized types of neurons. Intracellular recording and staining methods enabled us to show that PNs with arborizations in an identified glomerulus were more sensitive to $(+)$ linalool than to $(-)$ linalool over a range of concentrations (Fig. 6). Moreover, at low concentrations, in the range close to that found in natural stimuli (Fraser et al., 2003), some latLGFPNs did not respond to (-)linalool (Fig. 4).

In Manduca females, a calcium-imaging study, in which odorevoked signals most likely reflected the activity of antennal ORCs, showed that $( \pm)$ linalool activated an area in proximity to, but more medial than, the LFGs (Hansson et al., 2003). Because the LFGs lie at a depth of 200-250 $\mu \mathrm{m}$ from the anterior surface of the AL, they cannot be properly imaged using conventional methods of fluorescence microscopy. A possible explanation for the reported observations, therefore, is that the source of the light emitted from deeper glomeruli might have been unclear or misinterpreted. Nevertheless, our results are consistent with the calcium-imaging data in that we also found that linalool activated PNs in sexually isomorphic glomeruli (Figs. 10, 11), although latLFG-PNs were more sensitive to and selective for linalool (compare Fig. 11 with Fig. 5). Moreover, it is likely that certain sexually isomorphic glomeruli are most responsive not to linalool but to one or more linalool-like odor compounds (Fig. 10).

It is known that structural features of odor compounds, such as their functional groups, carbon-chain length, and the presence of double bonds, determine the perceived odor quality (Laska et al., 2000; Kay et al., 2003; Wiltrout et al., 2003) as well as the ligand specificity of recognition by ORCs (Malnic et al., 1999; Araneda et al., 2000; Fuss and Korsching, 2001). In the rat olfactory bulb, patterns of glomerular activation are reportedly determined primarily by the functional groups of odor compounds (Johnson et al., 1998; Uchida et al., 2000), and structurally related odor compounds activate adjacent regions (Mori et al., 1992; Belluscio and Katz, 2001). In contrast, Sachse et al. (1999) reported that in honey bees, the molecular receptive ranges of glomeruli depend mainly on chain length, and information about functional groups is present only in the entire glomerular activity pattern. We found that the presence of the hydroxyl group in the linalool molecule is a key structural feature determinant for activating the inputs of certain PNs. The latLFG-PNs failed to respond to antennal stimulation with either enantiomeric form of citronellene, a compound lacking the hydroxyl moiety but otherwise identical to linalool, even when presented at high concentrations (Figs. 3, 7A). Other monoterpenoids that share structural features with linalool but do not bear a hydroxyl group also did not evoke a response. Other alcohols evoked responses but only at very high, probably nonphysiological, concentrations (Fig. 7B). Similar structure-activity relationships were observed for $(-)$ linalool-sensitive PNs (Fig. $10 \mathrm{~B}$ ). In contrast, the structural features of linalool that were required to activate nonenantioselective PNs were more variable. The presence of the hydroxyl group was necessary (but not sufficient) in the case of ADG-PNs, whereas some PNs with arborizations in other glomeruli responded equally well to structurally related compounds whether or not they possessed hydroxyl groups. Because each glomerulus is believed to receive synaptic input from ORCs expressing the same receptor protein (Gao et al., 2000; Vosshall et al., 2000), recordings from PNs are informative about the ligand specificities of the ORCs projecting to the glomeruli innervated by those PNs. Thus, our results are consistent with the idea that each ORC receptor recognizes specifically a key portion of an odor molecule (Malnic et al., 1999; Pilpel and Lancet, 1999; Araneda et al., 2000; Floriano et al., 2000; Singer, 2000; Uchida et al., 2000).

$(+)$ Linalool is an important component of the mateattractant pheromone in the solitary bee Collectes cunicularius. Behavioral studies showed that although both enantiomers elicited similar antennal responses, males clearly distinguish between the enantiomers (Borg-Karlson et al., 2003). The behavioral significance of linalool for Manduca, however, is incompletely understood. Linalool is one of many volatiles emitted by plants, including host plants of Manduca (Loughrin et al., 1990; Raguso and Pichersky, 1999; Fraser et al., 2003), but the enantiomeric composition of the released linalool has not been determined. Systemic release of linalool from the vegetative parts of tobacco (a Manduca host plant) in response to larval-feeding damage causes reduction in the rates of oviposition by Manduca females (De Moraes et al., 2001; Kessler and Baldwin, 2001). Thus, it is possible that the latLFG contributes to the sensory assessment of potential oviposition sites. Another possibility is that the latLFG processes information about components of a putative pheromone produced by a scent organ in the male moth (Birch et al., 1990). In this regard it is noteworthy that $(+)$ linalool is one of the components of the male pheromone in another moth species (Landolt and Heath, 1990).

Finally, the enantiomeric preferences of glomeruli processing sensory information about linalool suggest that the ratio of $(+)$ and $(-)$ enantiomers of linalool emitted by plants could be important for the behavior of females. Studies in progress address this possibility.

\section{References}

Andersen RA, Hamilton-Kemp TR, Loughrin JH, Hughes CG, Hildebrand DF, Sutton TG (1988) Green leaf headspace volatiles from Nicotiana tabacum lines of different trichome morphology. J Agric Food Chem 36:295-299.

Araneda RC, Kini AD, Firestein S (2000) The molecular receptive range of an odorant receptor. Nat Neurosci 3:1248-1255.

Belluscio L, Katz LC (2001) Symmetry, stereotypy, and topography of odorant representations in mouse olfactory bulbs. J Neurosci 21:2113-2122.

Birch MC, Poppy GM, Baker TC (1990) Scents and eversible scent structures of male moths. Annu Rev Entomol 35:25-58.

Borg-Karlson A-K, Tengö J, Valterová I, Unelius CR, Taghizadeh T, Tolasch T, Francke W (2003) (S)-(+)-Linalool, a mate attractant pheromone component in the bee Colletes cunicularius. J Chem Ecol 29:1-14.

Carlsson MA, Galizia CG, Hansson BS (2002) Spatial representation of odours in the antennal lobe of the moth Spodoptera littoralis (Lepidoptera: Noctuidae). Chem Senses 27:231-244.

Christensen TA, Hildebrand JG (1987) Male-specific, sex pheromoneselective projection neurons in the antennal lobes of the moth Manduca sexta. J Comp Physiol [A] 160:553-569.

Cometto-Muñiz JE, Cain WS, Abraham MH (2003) Quantification of chemical vapors in chemosensory research. Chem Senses 28:467-477.

De Moraes CM, Mescher MC, Tumlinson JH (2001) Caterpillar-induced nocturnal plant volatiles repel conspecific females. Nature 410:577-580.

Floriano WB, Vaidehi N, Goddard III WA, Singer MS, Shepherd GM (2000) Molecular mechanisms underlying differential odor responses of a mouse olfactory receptor. Proc Natl Acad Sci USA 97:10712-10716.

Fraser AM, Mechaber W, Hildebrand JG (2003) Electroantennographic responses of the sphinx moth Manduca sexta to host plant volatiles. J Chem Ecol 29:1813-1833. 
Friedman L, Miller JG (1971) Odor incongruity and chirality. Science 172:1044-1046.

Friedrich RW, Korsching SI (1997) Combinatorial and chemotopic odorant coding in the zebrafish olfactory bulb visualized by optical imaging. Neuron 18:737-752.

Friedrich RW, Korsching S (1998) Chemotopic, combinatorial, and noncombinatorial odorant representations in the olfactory bulb revealed using a voltage-sensitive axon tracer. J Neurosci 18:9977-9988.

Fuss SH, Korsching SI (2001) Odorant feature detection: activity mapping of structure response relationships in the zebrafish olfactory bulb. J Neurosci 21:8396-8407.

Gao Q, Yuan B, Chess A (2000) Convergent projections of Drosophila olfactory neurons to specific glomeruli in the antennal lobe. Nat Neurosci 3:780-785.

Hansson BS, Carlson JR, Kalinovà B (2003) Olfactory activation patterns in the antennal lobe of the sphinx moth, Manduca sexta. J Comp Physiol [A] 189:301-308.

Homberg U, Montague RA, Hildebrand JG (1988) Anatomy of antennocerebral pathways in the brain of the sphinx moth Manduca sexta. Cell Tissue Res 254:255-281.

Joerges J, Küttner A, Galizia CG, Menzel R (1997) Representations of odours and odour mixtures visualized in the honeybee brain. Nature 387:285-288.

Johnson BA, Woo CC, Leon M (1998) Spatial coding of odorant features in the glomerular layer of the rat olfactory bulb. J Comp Neurol 393:457-471.

Kay LM, Lowry CA, Jacobs HA (2003) Receptor contributions to configural and elemental odor mixture perception. Behav Neurosci 117:1108-1114.

Kessler A, Baldwin IT (2001) Defensive function of herbivore-induced plant volatile emissions in nature. Science 291:2141-2144.

Landolt PJ, Heath RR (1990) Sexual role reversal in mate-finding strategies of the cabbage lopper moth. Science 249:1026-1028.

Laska M, Galizia CG (2001) Enantioselectivity of odor perception in honeybees (Apis mellifera carnica). Behav Neurosci 115:632-639.

Laska M, Teubner P (1999) Olfactory discrimination ability of human subjects to ten pairs of enantiomers. Chem Senses 24:161-170.

Laska M, Ayabe-Kanamura S, Hübener F, Saito S (2000) Olfactory discrimination ability for aliphatic odorants as a function of oxygen moiety. Chem Senses 25:189-197.

Leal WS (1996) Chemical communication in scarab beetles: reciprocal behavioral agonist-antagonist activities of chiral pheromones. Proc Natl Acad Sci USA 93:12112-12115.

Lehmkuhle MJ, Normann RA, Maynard EM (2003) High-resolution analysis of the spatio-temporal activity patterns in rat olfactory bulb evoked by enantiomer odors. Chem Senses 28:499-508.

Lei H, Christensen TA, Hildebrand JG (2002) Local inhibition modulates odor-evoked synchronization of glomerulus-specific output neurons. Nat Neurosci 5:557-565.

Linster C, Johnson BA, Yue E, Morse A, Xu Z, Hingco EE, Choi Y, Choi M, Messiha A, Leon M (2001) Perceptual correlates of neural representations evoked by odorant enantiomers. J Neurosci 21:9837-9843.

Linster C, Johnson BA, Morse A, Yue E, Leon M (2002) Spontaneous versus reinforced olfactory discriminations. J Neurosci 22:6842-6845.

Loughrin JH, Hamilton-Kemp TR, Andersen RA, Hildebrand DF (1990) Headspace compounds from flowers of Nicotiana tabacum and related species. J Agric Food Chem 38:455-460.

Ma M, Shepherd GM (2000) Functional mosaic organization of mouse olfactory receptor neurons. Proc Natl Acad Sci USA 97:12869-12874.

Malnic B, Hirono J, Sato T, Buck L (1999) Combinatorial receptor codes for odors. Cell 96:713-723.

Mombaerts P, Wang F, Dulac C, Chao SK, Nemes A, Mendelsohn M, Edmondson J, Axel R (1996) Visualizing an olfactory sensory map. Neuron $87: 675-686$.

Mori K (1998) Chirality and insect pheromones. Chirality 10:578-586.

Mori K (2002) Chirality in the natural world: chemical communications. In: Chirality in natural and applied science (Lough WJ, Wainer JW, eds), pp 241-259. Oxford: Blackwell.

Mori K, Mataga N, Imamura K (1992) Differential specificities of single mitral cells in rabbit olfactory bulb for a homologous series of fatty acid odor molecules. J Neurophysiol 67:786-789.

Ng M, Roorda RD, Lima SQ, Zemelman BV, Morcillo P, Miesenbock G (2002) Transmission of olfactory information between three populations of neurons in the antennal lobe of the fly. Neuron 36:463-474.
Pilpel Y, Lancet D (1999) The variable and conserved interfaces of modeled olfactory receptor proteins. Protein Sci 8:969-977.

Raguso RA, Pichersky E (1999) A day in the life of a linalool molecule: chemical communication in a plant-pollinator system. Part 1: Linalool biosynthesis in flowering plants. Plant Species Biol 14:95-120.

Roche King J, Hildebrand JG (1999) Sexually isomorphic olfactory glomeruli in the antennal lobes of the moth Manduca sexta. Soc Neurosci Abstr 25:124.

Roche King J, Christensen TA, Hildebrand JG (2000) Response characteristics of an identified, sexually dimorphic olfactory glomerulus. J Neurosci 20:2391-2399.

Rospars JP, Hildebrand JG (2000) Sexually dimorphic and isomorphic glomeruli in the antennal lobes of the sphinx moth Manduca sexta. Chem Senses 25:119-129.

Rubin BD, Katz LC (1999) Optical imaging of odorant representations in the mammalian olfactory bulb. Neuron 23:499-511.

Rubin BD, Katz LC (2001) Spatial coding of enantiomers in the rat olfactory bulb. Nat Neurosci 4:355-356.

Sachse S, Galizia CG (2002) Role of inhibition for temporal and spatial odor representation in olfactory output neurons: a calcium imaging study. J Neurophysiol 87:1106-1117.

Sachse S, Galizia CG (2003) The coding of odour-intensity in the honeybee antennal lobe: local computation optimizes odour representation. Eur J Neurosci 18:2119-2132.

Sachse S, Rappert A, Galizia CG (1999) The spatial representation of chemical structures in the antennal lobe of honeybees: steps towards the olfactory code. Eur J Neurosci 11:3970-3982.

Selchow K (1998) Processing of plant-associated odors by a subset of projection neurons in the antennal lobe of the female moth Manduca sexta. $\mathrm{PhD}$ thesis, University of Arizona.

Singer MS (2000) Analysis of the molecular basis for octanal interactions in the expressed rat I7 olfactory receptor. Chem Senses 25:155-165.

Slotnick B, Bisulco S (2003) Detection and discrimination of carvone enantiomers in rats with olfactory bulb lesions. Neuroscience 121:451-457.

Stranden M, Borg-Karlson A-K, Mustaparta H (2002) Receptor neuron discrimination of the germacrene D enantiomers in the moth Helicoverpa armigera. Chem Senses 27:143-152.

Stranden M, Liblikas I, König WA, Almaas TJ, Borg-Karlson A-K, Mustaparta H (2003) (-)-Germacrene D receptor neurons in three species of heliothine moths: structure-activity relationships. J Comp Physiol [A] 189:563-577.

Tumlinson JH, Klein MG, Doolittle RE, Ladd TL, Proveaux AT (1977) Identification of the female Japanese beetle sex pheromone: inhibition of male response by an enantiomer. Science 197:789-792.

Uchida N, Takahashi YK, Tanifuji M, Mori K (2000) Odor maps in the mammalian olfactory bulb: domain organization and odorant structural features. Nat Neurosci 3:1035-1043.

Vickers NJ, Christensen TA, Hildebrand JG (1998) Combinatorial odor discrimination in the brain: attractive and antagonist odor blends are represented in distinct combinations of uniquely identifiable glomeruli. J Comp Neurol 400:35-56.

Vosshall LB, Wong AM, Axel R (2000) An olfactory sensory map in the fly brain. Cell 102:147-159.

Wachowiak M, Cohen LB (2001) Representation of odorants by receptor neuron input to the mouse olfactory bulb. Neuron 32:723-735.

Wachowiak M, Cohen LB (2003) Correspondence between odorantevoked patterns of receptor neuron input and intrinsic optical signals in the mouse olfactory bulb. J Neurophysiol 89:1623-1639.

Wang JW, Wong AM, Flores J, Vosshall LB, Axel R (2003) Two-photon calcium imaging reveals an odor-evoked map of activity in the fly brain. Cell 112:271-282.

Wibe A, Borg-Karlson A-K, Persson M, Norin T, Mustaparta H (1998) Enantiomeric composition of monoterpene hydrocarbons in some conifers and receptor neuron discrimination of $\alpha$-pinene and limonene enantiomers in the pine weevil, Hylobius abietis. J Chem Ecol 24:273-287.

Wilson RI, Turner GC, Laurent G (2004) Transformation of olfactory representations in the Drosophila antennal lobe. Science 303:366-370.

Wiltrout C, Dogra S, Linster C (2003) Configurational and nonconfigurational interactions between odorants in binary mixtures. Behav Neurosci 117:236-245.

Zar JH (1999) Biostatistical analysis, Ed 4. Upper Saddle River, NJ: PrenticeHall. 